\title{
Análise da Espessura Ótica dos Aerossóis do Sensor OMI na America do Sul
}

\author{
Paulo Antunes Dias Pereira Calado ${ }^{1}$ (D), Emylle Isabele Gonçalves Barbosa ${ }^{1}$ (D), \\ Glauber Lopes Mariano ${ }^{1}$ \\ ${ }^{1}$ Instituto de Ciencias Atmosfericas, Universidade Federal de Alagoas, Alagoas, AL, Brasil.
}

Recebido em: 5 de Julho de 2020 - Aceito em: 29 de Dezembro de 2020

\begin{abstract}
Resumo
Este trabalho pretende avaliar o comportamento da EOA (espessura ótica dos aerossóis) sobre regiões da América do Sul (Cone Sul, Amazônia legal, do Nordeste do Brasil e Sul do Brasil), com característica climáticas diversas, analisando seu comportamento médio para o período dos anos de 2005 a 2019. Os dados são coletados pelo sensor OMI (Ozone monitoring Instrument) da NASA (National Aeronautics and Space Administration) a bordo do satélite Aura com resolução espacial de $1^{\circ} \times 1^{\circ}$ e resolução temporal diária. Dos dados utilizados foram feitas médias e percentis, foi observado que existe um comportamento sazonal nos locais analisados, com maiores valores $(0,35$ e 0,34$)$ encontrados nas estações secas e menores nas estações chuvosas $(0,15$ e 0,16$)$. Ao analisar sistemas que influenciam e os períodos de chuva e de seca das regiões, foi observado a relação da concentração de aerossóis com a precipitação, pois os valores máximos de aerossóis acontecem nas estações secas e esse padrão se repete em todas regiões com exceção da região Nordeste onde fatores além dos climatológicos parecem ter uma maior influencia. É levantada como uma das hipóteses a influencia antropogênica tendo em vista os altos níveis de emissões das grandes capitais no litoral da região.
\end{abstract}

Palavras-chave: poluição atmosférica, aerossóis, sensoriamento remoto.

\section{Analysis of the Optical Thickness of the Aerosols From OMI Sensor in South America}

\begin{abstract}
This work aims to evaluate the behavior of AOD (aerosol optical depth) over South American regions (Southern Cone, Legal Amazon, Northeastern Brazil and Southern Brazil), with different climate characteristics, analyzing their average behavior for the period from 2005 to 2019. The data are collected from OMI (Ozone Monitoring Instrument) sensor of NASA (National Aeronautics and Space Administration) aboard the Aura satellite with spatial resolution of $1^{\circ} \times 1^{\circ}$ and daily temporal resolution. From the data used, were made averages and percentiles, it was observed that there is a seasonal behavior in all the analyzed locations, with highest values $(0.35$ and 0.34$)$ being found in the dry seasons and lowest in the rainy seasons $(0.15$ and 0.16$)$. When analyzing influencing systems and the periods of rain and drought in the regions, it was possible to observe the relationship between the concentration of aerosols and precipitation, as the maximum values of aerosols occur in the drier seasons and this pattern is repeated in all regions except from the Northeastern region where other factors than climatological seem to have a greater influence, the anthropogenic influence is one of the hypotheses due to the location of the largest capitals of the region at the coast.
\end{abstract}

Keywords: atmospheric pollution, aerosols, remote sensing.

\section{Introdução}

Quando se trata de observar os impactos ambientais da poluição atmosférica os aerossóis tem extrema relevância, pois afetam fortemente o balanço radiativo, o clima, a química da atmosfera, a visibilidade, e a saúde das pessoas expostas às altas concentrações de partículas, desde a escala local até a escala regional e global (Artaxo, 2006). O diâmetro dos aerossóis atmosféricos varia entre 0,01 e $10 \mu \mathrm{m}$ e isso é de fundamental importância, pois alguns autores descrevem as partículas de acordo com sua

Autor de correspondência: Paulo Antunes Dias Pereira Calado, paulo.antunes.dias.p@gmail.com. 
forma, tamanho e composição química (Finlayson-Pitts e Pitts, 1999). Na meteorologia, o aerossol usualmente é caracterizado como $\mathrm{PM}_{2,5}$ (partículas de diâmetro inferior a 2,5 micrometros) ou $\mathrm{PM}_{10}$ (partículas de diâmetro inferior a 10 micrometros) (NASA, 2013).

Os aerossóis segundo Seinfeld e Pandis (2006) são divididos em dois grupos: primário, constituídos por partículas emitidas diretamente para a atmosfera; e secundários, formados na própria atmosfera na conversão de gás/ partícula. Uma das principais características dos aerossóis são suas fontes e no caso das partículas primárias, essas podem ser múltiplas, naturais ou antropogênicas, abrangendo os processos de combustão, as erupções vulcânicas, as queimadas, as emanações derivadas de certas atividades industriais, o "spray" marinho e alguns materiais biológicos (Alves, 2005). As queimadas são uma das principais fontes de partícula primaria, se tornando uma das maiores preocupações ambientais devido a aumento da ocorrência nas últimas cinco décadas, podendo ter diversas causas como às questões do desmatamento generalizado, da degradação florestal e fatores políticos e econômicos (Crutzen e Andreae, 1990; Bustamante et al., 2016).

Segundo Rosário (2011) ao analisar a espessura ótica dos aerossóis na América do sul o maior destaque da região é observado na pluma associada às queimadas na região central do subcontinente no período de agosto a outubro. Entretanto analisando os resultados obtidos em sua pesquisa existem outras regiões que têm importante papel na dinâmica e na distribuição espacial e temporal da concentração dos aerossóis sobre o subcontinente como, por exemplo, as áreas metropolitanas (São Paulo e Buenos Aires) que emitem considerável quantidade de material particulado para a atmosfera gerando plumas locais com profundidades ópticas significativas.

Segundo Siqueira (2016) durante as estações secas os aerossóis na América do Sul possuem um grande aumento de seus valores, isto é esperado devido ao aumento no número de focos de calor que são segundo Gontijo et al. (2011) pontos geográficos captados por sensores espaciais na superfície da Terra quando detectados a uma temperatura acima de $47{ }^{\circ} \mathrm{C}$, o monitoramento feito a partir desses focos é adequado para regiões remotas que são afetadas por queimadas e não tem outro meio de detecção em tempo-real (Setzer e Morelli, 2011), para esse monitoramento o Sensoriamento Remoto junto aos Sistemas de Informação Geográfica (SIG) são ferramentas eficazes (Pereira et al., 1997). Já nas estações chuvosas os aerossóis são usados como núcleos de condensação, e à medida que acontecem as precipitações, eles acabam sendo removidos da atmosfera diminuindo assim suas concentrações.

Segundo Powder (2003) em relação ao transporte dos aerossóis, as circulações atmosféricas de escala global e sinótica influenciam de forma em que impactos radiativos de aerossóis aconteçam em locais bastante distantes de sua origem, como é o caso do estudo realizado por Si- queira (2016) na América do Sul durante a estação seca utilizando dados do MODIS (Moderate-Resolution Imaging Spectroradiometer) e dados do modelo BRAMS (Brazilian developments on the Regional Atmospheric Modelling System), no qual demonstra que é possível observar, a pluma de fumaça sendo transportada para longas distâncias de seus locais de origem. Um dos grandes responsáveis por esse transporte é o jato de baixos níveis (JBN) como podemos observar no estudo de transporte de longo alcance realizado por Martins et al. (2018) para identificar as influências diretas do JBN no transporte de aerossóis da região central do Brasil para a região sul do país, contribuindo para maiores valores observados de material particulado na região sul em dias com JBN (dia 17 e 18 de agosto e 12 a 14 de setembro). Já no estudo realizado por Recuero et al. (2004) foi analisado o transporte de plumas de aerossóis durante a estação de queimadas no ano de 2002, nas regiões de Ji-Paraná e Brasil Central. Foi constatado que as partículas de queima de biomassa sofrem influencia de sistemas como a Zona de Convergência Intertropical (ZCIT), sistemas frontais e sistemas de pressão como a Alta Subtropical do Atlântico Sul (ASAS), além da circulação de grande escala.

A distribuição dos aerossóis é heterogênea na atmosfera e as diferenças das características citadas anteriormente (tamanho, propriedades químicas, fontes emissoras e de tempo de vida médio) tornam o processo de coleta de dados algo bem especifico, sendo assim um dos principais motivos para o uso de sensoriamento remoto para tal tarefa (Kaufman et al. 2002). O predomínio de aerossóis antropogênicos, sobre a área continental significa que a composição, precipitação, o ciclo hidrológico e os sistemas de circulação atmosférica são todos afetados tanto pelos impactos radiativos quanto pelos microfísicos dos aerossóis (Kaufman e Koren, 2006).

$\mathrm{O}$ OMI tem um desempenho bem satisfatório quando comparado a dados de EOA de superfície como os da AERONET, como destacado por exemplo no trabalho efetuado por Bibi (2015) através de uma comparação multisensor MODIS $_{\mathrm{STD}}, \mathrm{MODIS}_{\mathrm{DB}}$ MISR, OMI e CALIPSO) com os dados de superfície pra 4 cidades (Karachi, Lahore, Jaipur e Kanpur) na região do sul da Ásia no período de 2007 a 2013. Nesse estudo o OMI obteve uma correlação com o fotômetro solar de $0.53 \mathrm{em}$ média, se saindo melhor do que outros sensores em algumas cidades. Um desempenho satisfatório do OMI também foi encontrado por Torres, O. et al. (2010) onde a diminuição observada no sinal OMI (em ambos Aerossol Profundidade Ótica de Índice e Absorção) e profundidade ótica de extinção MODIS em 2008 e 2009 na América do Sul se mostraram consistente com as estatísticas de contagem de fogo relatadas no estudo e que claramente indicavam uma redução real do número de incêndios no Sul América durante as temporadas de queimadas em 2008 e 2009. 
O objetivo desse estudo é analisar a espessura ótica dos aerossóis através de sensoriamento remoto utilizando o sensor OMI (Ozone monitoring Instrument) para o período de 15 anos (2005 a 2019) na América do Sul, o trabalho se divide em três seções na primeira delas (metodologia) é descrito o sensor OMI e a área estudada que foi dividida em 3 (três) com condições climáticas diversas Cone Sul (árido e frio), Amazônia internacional (Clima equatorial) e região Nordeste do Brasil (árido quente), já a seção seguinte descreve os resultados obtidos dentre eles o mais impactante é o efeito da precipitação na concentração dos aerossóis e como ele se comporta durante as estações e ao longo dos meses, na ultima seção é apenas descrito as conclusões obtidas dos resultados após a finalização do trabalho.

\section{Metodologia}

\subsection{Dados do sensor OMI}

Para a análise do EOA foram coletados dados em formato de grade com resolução espacial de $1^{\circ} \times 1^{\circ} \mathrm{e}$ resolução temporal diária referente a três áreas das regiões da América do Sul (Fig. 1).

Os dados coletados no período de 2005 a 2019 são oriundos do sensor OMI instalado e lançado a bordo do satélite Aura em 2004. O objetivo principal do OMI é obter medições globais em alta resolução espacial e espectral de uma série de gases traços na troposfera e estratosfera (Levelt, 2006). Ele pode distinguir entre tipos de aerossóis, como fumaça, poeira e sulfatos (Duncan, 2013). Segundo Torres (2013), isso é realizado através do algo-

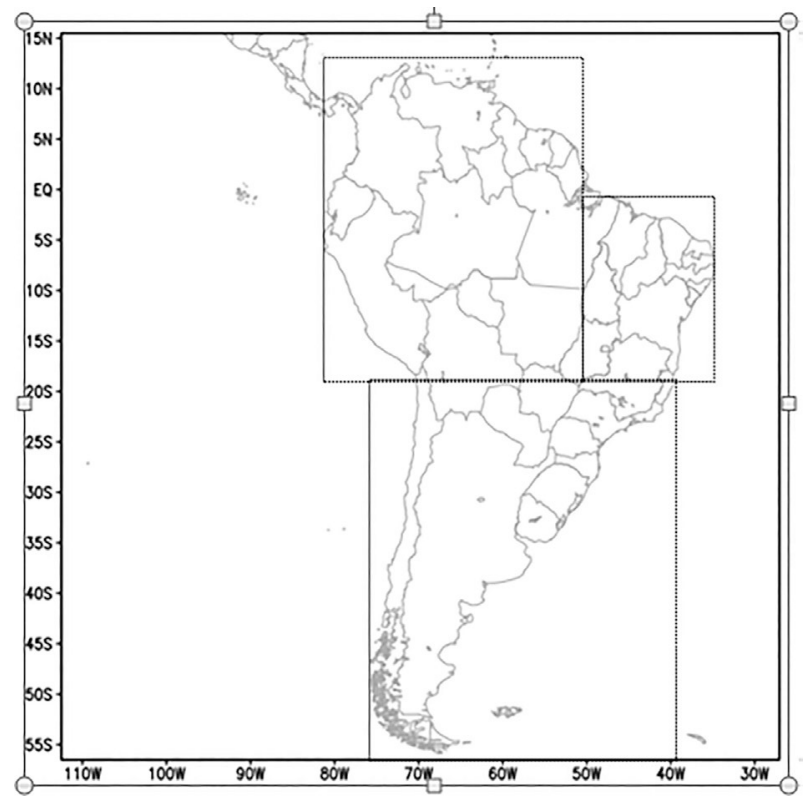

Figura 1 - Mapa da América do sul com as três regiões que foram utilizadas para estudo demarcadas por quadriláteros. ritmo OMAERUV que usa refletâncias pré-computadas da parte superior da atmosfera para um conjunto de 21 modelos de aerossóis composto por três tipos de aerossóis (poeira, aerossóis carbonáceos aerossóis à base de sulfato).

Como é descrito na propria pagina do projeto o OMI é um espectrógrafo de imagem de visualização do nadir que mede a radiação solar retroespalhada pela atmosfera e superfície da Terra em toda a faixa de comprimento de onda de 270 a $500 \mathrm{~nm}$ com uma resolução espectral de cerca de $0,5 \mathrm{~nm}$. A proporção da radiância e irradiância calibradas é igual à função de distribuição de espalhamento bidirecional atmosférico da Terra (BSDF). A luz que entra no telescópio é despolarizada usando um scrambler e então dividida em dois canais: o canal UV com faixa de comprimento de onda 270-380 nm e o canal VIS com faixa de comprimento de onda 350-500 nm (Levelt, 2006). Esses fatores são importantes para a obtenção da cocentração de gases traços e para permitir que o OMI monitore fenômenos de poluição troposférica como queima de biomassa e poluição industrial, pois o registro da poluição troposférica é essencial para estudar o impacto humano na atmosfera da Terra e clima (Dobber, 2006).

Uma comparação multisensor (MODIS, MISR,

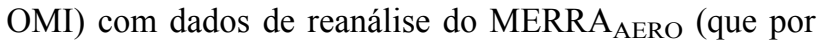
sua vez foram validados por dados de superfície da AERONET no mesmo estudo) para a poeira no Saara foi efetuado por Buchard (2015), neste estudo o sensor OMI obteve um desempenho ainda melhor com uma correlação média de 0.62 no período para o ano de 2007.

\section{2. Áreas de estudo}

No presente artigo o continente sul-americano foi dividido em 3 áreas (Fig. 1) são elas a região do Cone Sul (Argentina, Chile, Peru, Equador e Bolívia), Amazônia Internacional e Nordeste Brasileiro. Essas regiões foram escolhidas por possuírem características diversas, como por exemplo, a influencia de relevos como os Andes ou de sistemas, tais como a Zona de Convergência do Atlântico Sul (ZCAS) (Kodama, 1992 ; Carvalho et al., 2004), a Zona de Convergência Intertropical (ZCIT) (UVO, 1989), a Alta da Bolívia e o cavado do Nordeste (AB/CV) (Lenters e Cook, 1997), as Altas Subtropicais do Atlântico e do Pacífico (Rodwell e Hoskins, 2001), os sistemas frontais (SF) (Andrade, 2005), o Jato de Baixos Níveis (JBN) (Marengo et al., 2004).

Todas as regiões possuem tipos de clima diversos segundo a classificação climática de Koppen-Geiger (Peel, 2007), dentre eles estão: árido e quente, árido e frio, semiárido e frio, mediterrânico e verão fresco, subtropical úmido e oceânico temperado, (BWh, BWk, BSk, Csb, Cfa e $\mathrm{Cfb}$ ) para a região dos Cone Sul, Clima equatorial, de monção, de savana, subtropical úmido e mediterrânico e verão fresco (Af, Am, Aw/As, Cfa e Csb) para a região da 
Amazônia internacional e árido quente, savana e semiárido quente (BSh, BWh e Aw/As) para a região Nordeste.

\subsubsection{Amazônia Internacional (Norte da América do Sul)}

Amazônia Internacional (quadrilátero com latitudes $-19^{\circ}$ e $-12.5^{\circ} \mathrm{S}$ e de longitudes $-82^{\circ}-53^{\circ} \mathrm{W}$ ) é o nome pelo qual é conhecida uma vasta região ao norte da América do Sul, compreendendo uma boa parte do território brasileiro mais a totalidade do território de outros oito países: Guiana, Guiana Francesa, Suriname, Equador, Colômbia, Venezuela, Bolívia e Peru (Aragón, 2018).

A estação chuvosa na Bacia Amazônica ocorre entre os meses de novembro a março. Neste período, a concentração de partículas de aerossol nas nuvens é baixa (em

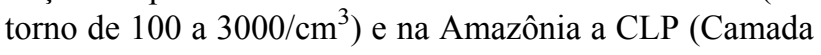
Limite Planetária) é parcialmente limpa. Os picos de concentração de aerossóis ocorrem apenas quando os ventos vem do sudeste, o que representa a advecção da cidade de Manaus (Artaxo et al., 2005). Já na estação seca, que ocorre entre os meses de maio e setembro, a concentração de partículas é alta $\left(15000\right.$ a $\left.30000 / \mathrm{cm}^{3}\right)$, pois a queima de biomassa não é mais reprimida pelas precipitações intensas. Essa concentração influencia o clima de forma direta, pois aumenta o espalhamento da radiação, o que pode afetar a taxa fotossintética, além do balanço regional do carbono (Ahlm et al., 2010).

\subsubsection{Cone Sul}

O Cone Sul (quadrilátero com latitudes de $-56^{\circ}$ e $-21^{\circ} \mathrm{S}$ e longitudes $-76^{\circ}-55^{\circ} \mathrm{W}$ ) é uma região ao sul do Trópico de Capricórnio composta pelas zonas austrais da América do Sul, formando uma espécie de grande península que define o sul do subcontinente. As características mais impactantes do relevo da região são as cordilheiras dos Andes, que no Cone Sul adquire as maiores altitudes do hemisfério sul. Em contrapartida, também estão as maiores depressões continentais do hemisfério sul (Grande Depressão de San Julián).

A região do Cone sul possui regiões com características climáticas bem singulares dentre elas a mais relevante para o estudo de aerossóis são as diferenças no ciclo anual de precipitação e a interferência de diferentes sistemas meteorológicos expecificos. A região do sudoeste da América do Sul, por exemplo, composto pelo centro-sul do Chile e extremo oeste do centro-sul da Argentina, possui ciclo anual da precipitação com máximo no inverno e mínimo no verão devido à influência do Anticiclone Subtropical do Pacífico Sul. A pouca precipitação no setor sul é devido aos ventos de oeste que transpõem os Andes, pois, em geral, ocorre precipitação a barlavento da topografia, o que faz com que o ar chegue seco a sotavento (Aceituno, 1980). No Centro-leste da Argentina e centronorte do Paraguai encontram-se os maiores totais pluviométricos nos meses do verão e menores durante o inverno. No verão, os ventos alísios de nordeste estão mais intensos
(Drumond et al., 2008; Durán-Quesada et al., 2009), assim adentram o continente transportando umidade. Esses ventos cruzam a bacia Amazônica e ao encontrarem os Andes no setor norte sofrem levantamento orográfico e contribuem para a precipitação (Garreaud e Wallace, 1997). Já a região formada pelo sul do Brasil, sul do Paraguai e Uruguai, tem precipitação bem distribuída ao longo do ano e com totais pluviométricos elevados. Os totais ainda são maiores no oeste do sul do Brasil na fronteira com o Paraguai. Diferentes sistemas atmosféricos influenciam a precipitação na região ao longo do ano, ou seja, os sistemas frontais, os ciclones, os CCM (Complexo Convectivo de Mesoescala) e linhas de instabilidade (Reboita et al., 2009c).

\subsubsection{Nordeste brasileiro}

Localizada aproximadamente no quadrilátero delimitado pelas latitudes de $0^{\circ} \mathrm{e}-20^{\circ}$ tem como principal características dois planaltos, o Borborema que é uma barreira topográfica para o escoamento atmosférico fazendo com que ventos de leste, ao a encontrarem, ascendam favorecendo precipitação orográfica no lado leste da montanha e, dessa forma, os ventos de leste chegam secos no sertão (Reboita et al., 2012) e a bacia do rio Parnaíba.

A precipitação na região ocorre devido diversos fenômenos meteorológicos conforme suas sazonalidades e local de atuação. Ao norte pode-se destacar a atuação da Zona de Convergência Intertropical (ZCIT) (Molion, 1987; Uvo et al., 1998) durante o verão. A região litorânea leste possui como destaque a influência de Ondas de Leste no inverno austral e Vórtices Ciclônicos de Altos Níveis (VCANs) no verão (Marengo et al. 2004). A região do semi-árido nordestino é caracterizada por um ciclo anual mostrando máximos de precipitação no verão/outono e mínimos no inverno.

\subsection{Estatística utilizada}

Neste trabalho foram utilizadas médias mensais e anuais para a análise do comportamento da EOA, além do percentil 99 para quantificar o número de casos em que a EOA apresenta valores elevados (valores de EOA $>$ Percentil 99).

Podemos observar nas formulas utilizadas para os resultados do p99 onde " $q$ " é uma amostra do percentil, " $x$ " é o percentil desejado e o " $n$ " é número de valores, sendo que a diferença dentre elas é dada pelo subscrito " $n$ ", a Eq. (1) é utilizada para situações de " $n$ " impar, já a Eq. (2) é utilizada para quando " $n$ " for par (Oliveira, 2013). Assim temos:

$$
q=x\left(\frac{[n+1]}{2}\right)
$$




$$
q=\frac{\mathrm{x}\left(\frac{n}{2}\right)+x\left(\left[\frac{\mathrm{n}}{2}\right]+1\right)}{2}
$$

\section{Resultados}

\subsection{Análise das médias anuais de EOA}

Na Fig. 2 são observadas as médias anuais de EOA e o p99 no período de 2005 a 2019 em todas as regiões do estudo. Nota-se que existe um comportamento semelhante entre as regiões estudadas dentre os anos analisados. A maior dentre as médias anuais analisadas se encontra no ano de 2006 para região da Amazônia internacional com o valor de 0,36, no ano de 2007 para a região do Cone Sul com o valor de 0,22 e no ano de 2010 para a região do Nordeste com o valor de 0,35 . Já ao observarmos o p99 não é visível um padrão de comportamento dentre os anos, porém podemos observar que os anos com os maiores valores acontecem em 2006 para a região do Amazônia internacional (com 1,0), no ano de 2007 nos andes $(0,40)$ sendo este o valor maior de toda a serie para essa região e no ano de 2010 para a região Nordeste com o valor de 0,67. Segundo o Instituto Nacional de Pesquisas Espaciais (INPE, 2005) analisando os dados de precipitação no setor sul da Amazônia, observou-se anomalias negativas durante a estação chuvosa de 2005 de $350 \mathrm{~mm}$ menores que a média histórica $(2.200 \mathrm{~mm})$. Isto pode ter contribuído para os altos valores de EOA durante os anos de 2005 e 2006.

$\mathrm{O}$ desmatamento também é um dos principais fatores que contribui para o aumento de aerossóis, de monóxido de carbono (CO) e outros gases de efeito estufa na atmosfera. Em 2005 foi estimado aproximadamente $18.793 \mathrm{~km}^{2}$ de desmatamento na região transformando todo o clima da região e induzindo várias queimadas (Fearnside, 2006).

O ano de 2010 apresentou também valores elevados de EOA quando comparados principalmente com os anos seguintes analisados. Ao observar um estudo realizado pelo INPE (Marengo et al., 2011), onde é efetuada a aná-

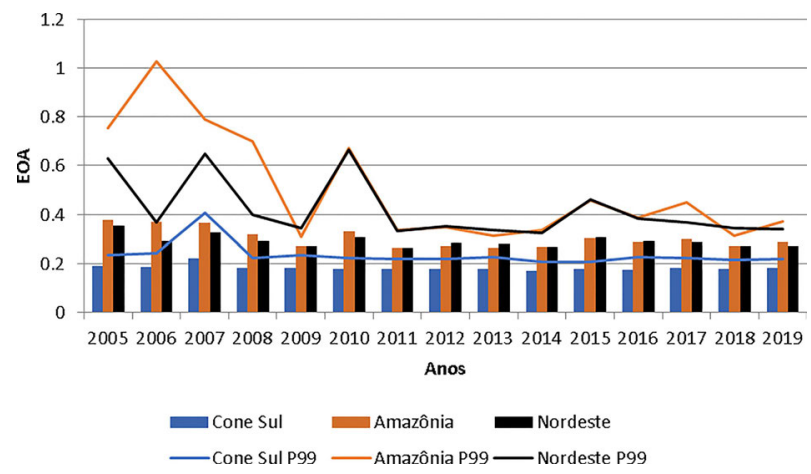

Figura 2 - Médias anuais (colunas) e p99 (linhas) da espessura ótica dos aerossóis do sensor OMI, para as regiões da Cone Sul(azul), Amazônia Internacional (laranja) e região Nordeste do Brasil (preto) para o período de 2005 a 2019 . lise da série histórica de dados de pluviosidade na região da bacia amazônica, destaca-se a seca ocorrida em 2010 como a mais drástica já registrada, superando a de 2005 , até então considerada a maior do século. $\mathrm{O}$ estudo aponta que o processo teve início no começo do verão, devido a atuação de um El Niño, mas foi intensificado pelo aquecimento das águas tropicais do Atlântico Norte. O resultado foi uma estação seca que se estendeu por muitos meses, ocasionando alterações no ciclo hidrológico em ambas as regiões durante o ano de 2010, com essa variação acontece também uma alteração nos valores de EOA.

No Cone sul os valores não possuem grandes variações além de apresentarem valores abaixo das outras duas regiões analisadas. Possivelmente isso ocorre a presença de uma precipitação homogênea ao longo do ano (Reboita et al., 2012).

Na Fig. 3 consta as médias sazonais e o p99 respectivamente para todas as regiões do estudo, para o período de 2005 a 2019. Ao analisar as médias expostas, é visível que existe um comportamento sazonal, os maiores valores se encontram nas estações do verão e primavera (estações secas) e os menores valores se encontram nas estação do inverno e outono (estações chuvosas) o que já era esperado devido a relação da variável de EOA com a precipitação e destacado através da apresentação na metodologia dos principais sistemas atuantes em cada região.

Também pode-se observar que a região do Cone sul possui valores bem menores que as outras regiões em todas as estações do ano, com máximo de 0,21 na primavera e mínimo de 0,15 no outono. O resultado mais alto da série se encontra na região da Amazônia internacional na estação da primavera com o valor de 0,35 e o menor se encontra no Cone Sul no outono com o valor de 0,15 .

\subsection{Cone Sul}

$\mathrm{Na}$ Fig. 4 são observadas as médias mensais de EOA para a região do Cone Sul no período de 2005 a 2019. Pode-se perceber que um padrão se repete ao

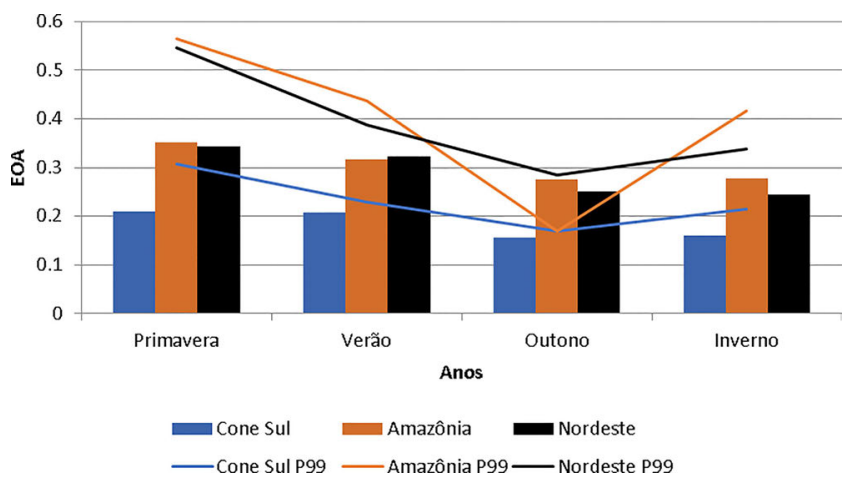

Figura 3 - Médias sazonais (colunas) e p99 (linhas) da espessura ótica dos aerossóis do sensor OMI, para as regiões do Cone Sul (azul), Amazônia Internacional (laranja) e região Nordeste do Brasil (preto) para o período de 2005 a 2019. 


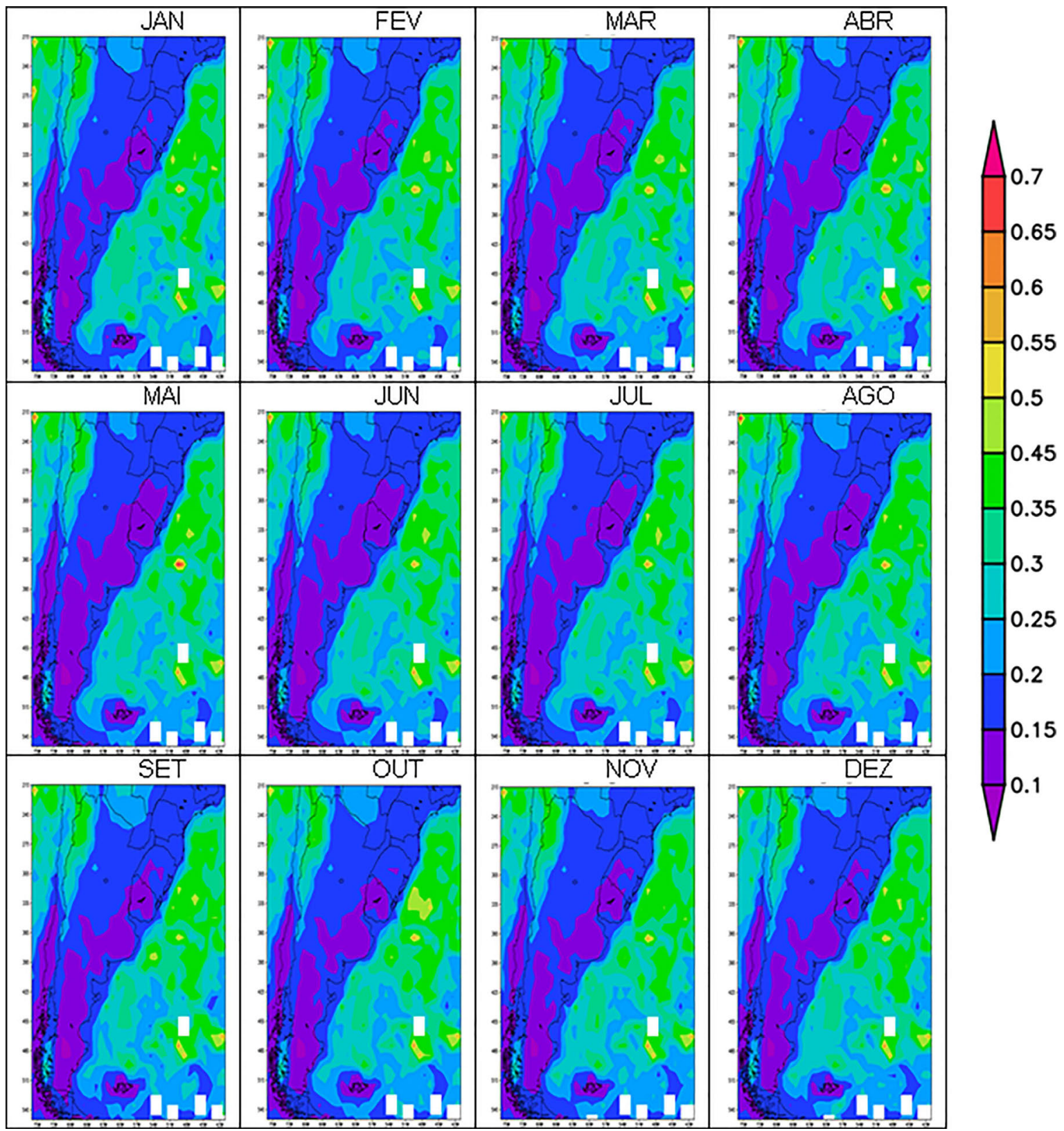

Figura 4 - Médias mensais de espessura ótica dos aerossóis do sensor OMI, na região do Cone Sul da América do Sul para o período de 2005 a 2019.

longo dos meses, com altos valores no norte do Chile (próximos a região da cordilheira dos Andes) e valores baixos no sul da Argentina, Chile e Brasil (entre 0,1 e $0,2)$. Os altos valores ocorrem pela pouca chuva na região, pois os movimentos descendentes do ASPS inibem a formação de chuva (Aceituno, 1980), outro fator que pode influenciar é a existência do Deserto do Atacama que é o deserto mais árido do mundo com uma precipitação de $100 \mathrm{~mm} / \mathrm{ano}$ (Betancourt et al., 2000), que pode contribuir para a concentração de aerossóis de poeira na atmosfera.
Ao observar a Fig. 5 nota-se que no cone sul como visto anteriormente as chuvas são bem distribuídas ao longo do ano sempre com maiores totais pluviométricos na estação do inverno e mínimo no verão (Reboita et al., 2012), essa mudança sazonal da precipitação e sua relação com EOA é visível sutilmente no gráfico onde os valores de EOA aumentam principalmente durante os meses do verão e primavera. Observando as médias sazonais, podese notar na estação do verão os valores mais altos que nas demais estações e os maiores deles (próximos a 0,5 ) se encontram próximo à Cordilheira dos Andes (Chile) e os 


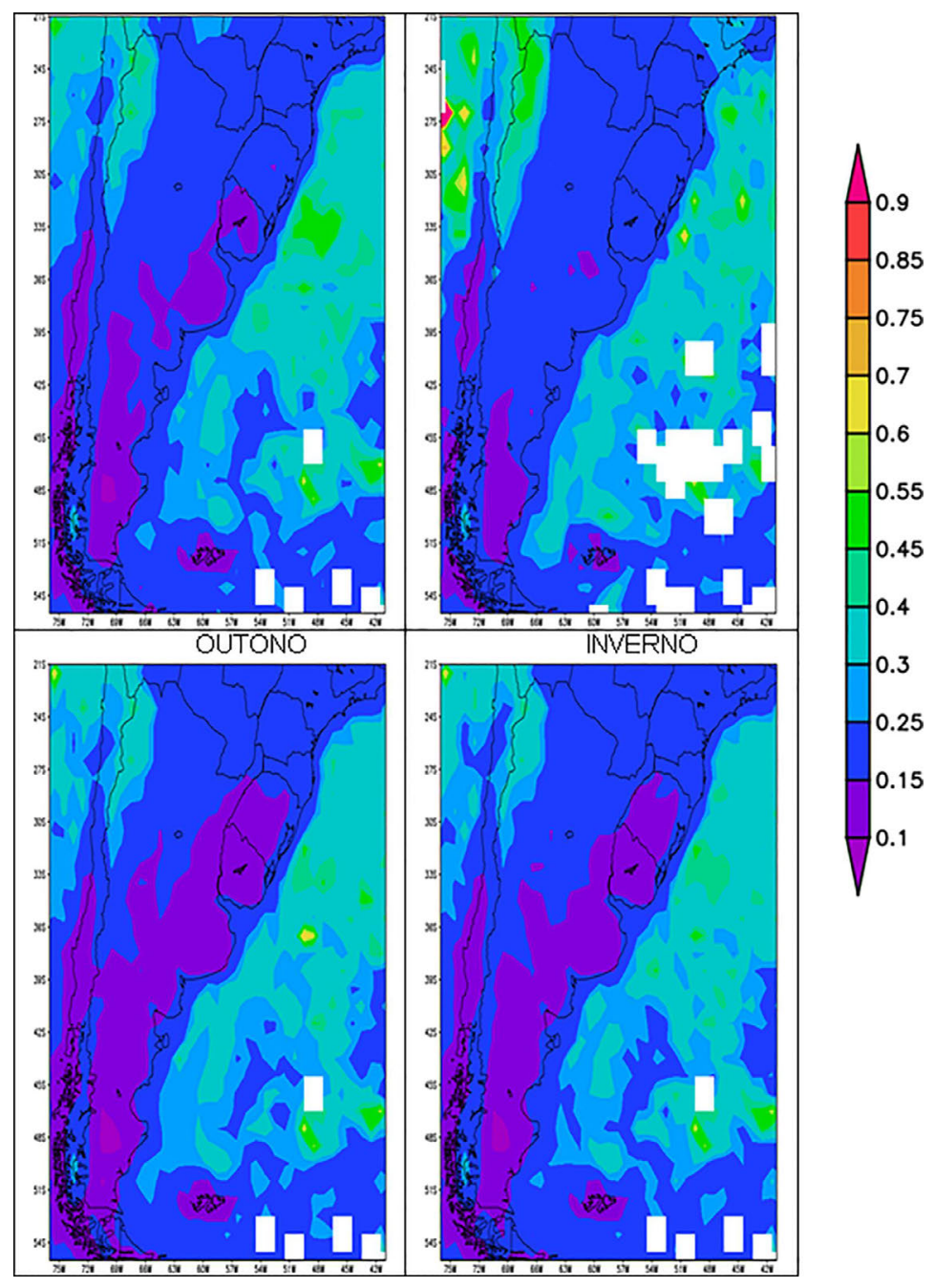

Figura 5 - Médias sazonais de espessura ótica dos aerossóis do sensor OMI, na região da cordilheira dos Andes para o período de 2005 a 2019.

menores valores $(0,1)$ ocorrem durante o outono na região sul da Argentina.

\subsection{Região da Amazônia Internacional (Norte da América do Sul)}

Na Fig. 6 são observadas as médias mensais de EOA para a região do Amazônia Internacional no período de 2005 a 2019. Pode-se notar que a região com os maiores valores, em todos os casos, se encontra no norte do estado de Rondônia principalmente no mês de setembro (com valores próximos a 0,65 ), assim como os menores se encontram no sul de Goiás (próximos de 0,15 ). Pode-se observar que na estação chuvosa na Amazônia, entre os meses de novembro a março, temos valores mais baixos de EOA em toda a região. Pois neste período, como citado por Artaxo et al. (2005) a concentração de partículas de aerossol na atmosfera (em torno de 100 a $3000 / \mathrm{cm}^{3}$ ).

Já na estação seca, entre maio a setembro, a concen-

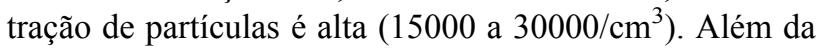
precipitação diminuir temos a ocorrência de queima de biomassa outro fator que afeta diretamente a concentração de EOA (Ahlm et al. 2010) contribuindo provavelmente assim para os valores encontrados no mês de setembro.

Observando a Fig. 7, a estação da primavera se destaca pelos altos valores principalmente na região no norte de Rondônia onde temos os maiores valores $(0,7)$. Valores semelhantes a estes acontecem na estação do verão na região da Bolívia, próximos ao norte do Chile e sul do Peru, já a estação com os menores valores é o outono (próximos a 0,1 ) no estado de Goiás. Como já comentado mostrando a relação da estação seca com o aumento do valora de EOA devido a diminuição da precipitação.

Segundo um estudo realizado por Paixão (2008) para a região da Amazônia com base na rede AERONET para o período de 1999 e 2005, no final da estação seca onde iniciam-se as queimadas (período entre agosto e outubro) a emissão de aerossóis aumenta abruptamente e a espessura óptica do aerossol aumenta cerca de 12 vezes (valor próximo a 0,9 ) nessa época, principalmente no mês de setembro (auge das queimadas). Um estudo semelhante foi realizado 


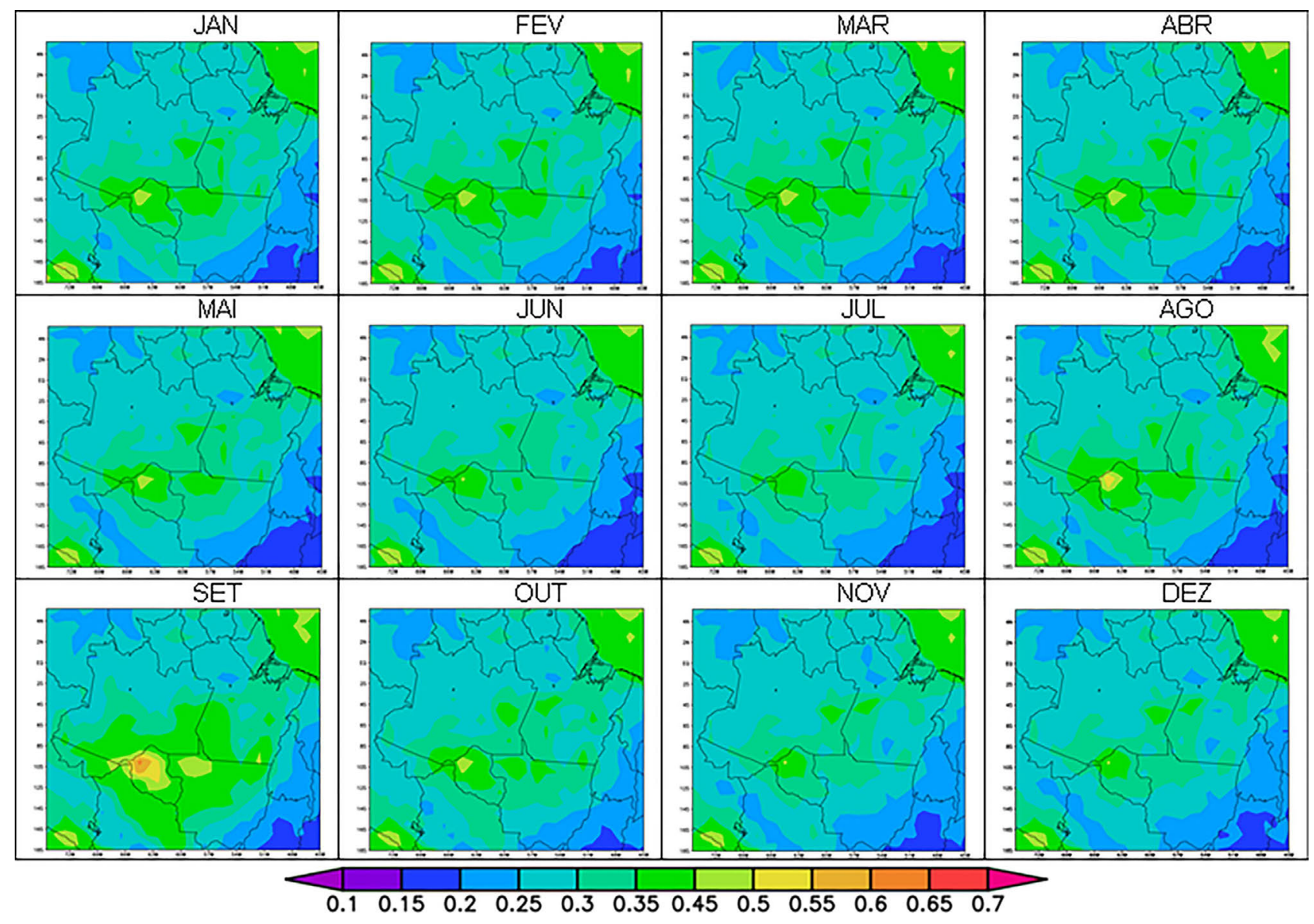

Figura 6 - Médias mensais de espessura ótica dos aerossóis do sensor OMI, na região da Amazônia Legal para o período de 2005 a 2019.

por Almeida (2016) para o periodo de Agosto a Outubro de 2012 na Amazônia durante a estação seca utilizando dados do MODIS e dados do modelo BRAMS (Brazilian developments on the Regional Atmospheric Modelling). O autor observou em setembro, no pico da estação seca, valores de Espessura ótica dos aerossóis acima de 0,8 no canal de $550 \mathrm{~nm}$. Os resultados foram semelhantes ao que consta na Fig. 6, com os máximos valores também ocorrendo no mês de setembro.

\subsection{Região Nordeste do Brasil}

Na Fig. 8 são observadas as médias mensais de EOA para a região Nordeste do Brasil no período de 2005 a 2019. Percebe-se que a região com os maiores valores, em todos os meses, se encontra no litoral do Maranhão próximo à cidade de São Luís no mês de outubro (próximos a $0,45)$, assim como os menores se encontram no sul da Bahia (próximo a 0,15 ).

Analisando a Fig. 9 onde constam as médias sazonais, observa-se o destaque para a estação do verão onde podemos observar altos valores na região sul do Maranhão (próximo a 0,5 ), já a estação com os menores valores é o outono (próximos a 0.15 ), principalmente na região sul da Bahia.

Tendo em vista que altos valores de precipitação na região norte do Nordeste Brasileiro devido à atuação da ZCIT (Molion, 1987; Uvo et al., 1998), podemos analisar os resultados levando em conta seus posicionamentos ao longo do ano. Observando que os máximos pluviométricos ocorrem durante o verão e o outono, onde o sistema se encontra mais ao sul, percebe-se, entretanto altos valores de EOA mesmo com a presença da chuva. Nas demais estações do ano, onde a ZCIT está para o norte e temos diminuição de precipitação sobre a região temos baixa concentração de EOA. Os resultados encontrados, divergindo das outras regiões já analisadas levanta a hipótese de existirem outros fatores mais determinantes, para a quantidade de aerossóis na Atmosfera do Nordeste, tanto para a região do litoral quando para a região do sertão.

A influência da brisa marítima e dos ventos alísios podem ser um dos fatores destacados devido ao transporte de aerossóis marinhos sobre a região contribuindo assim para o aumento da EOA no litoral da região analisada. Destaca-se também uma possível influência antropogênica tendo em vista que todas as grandes capitais da região nor- 

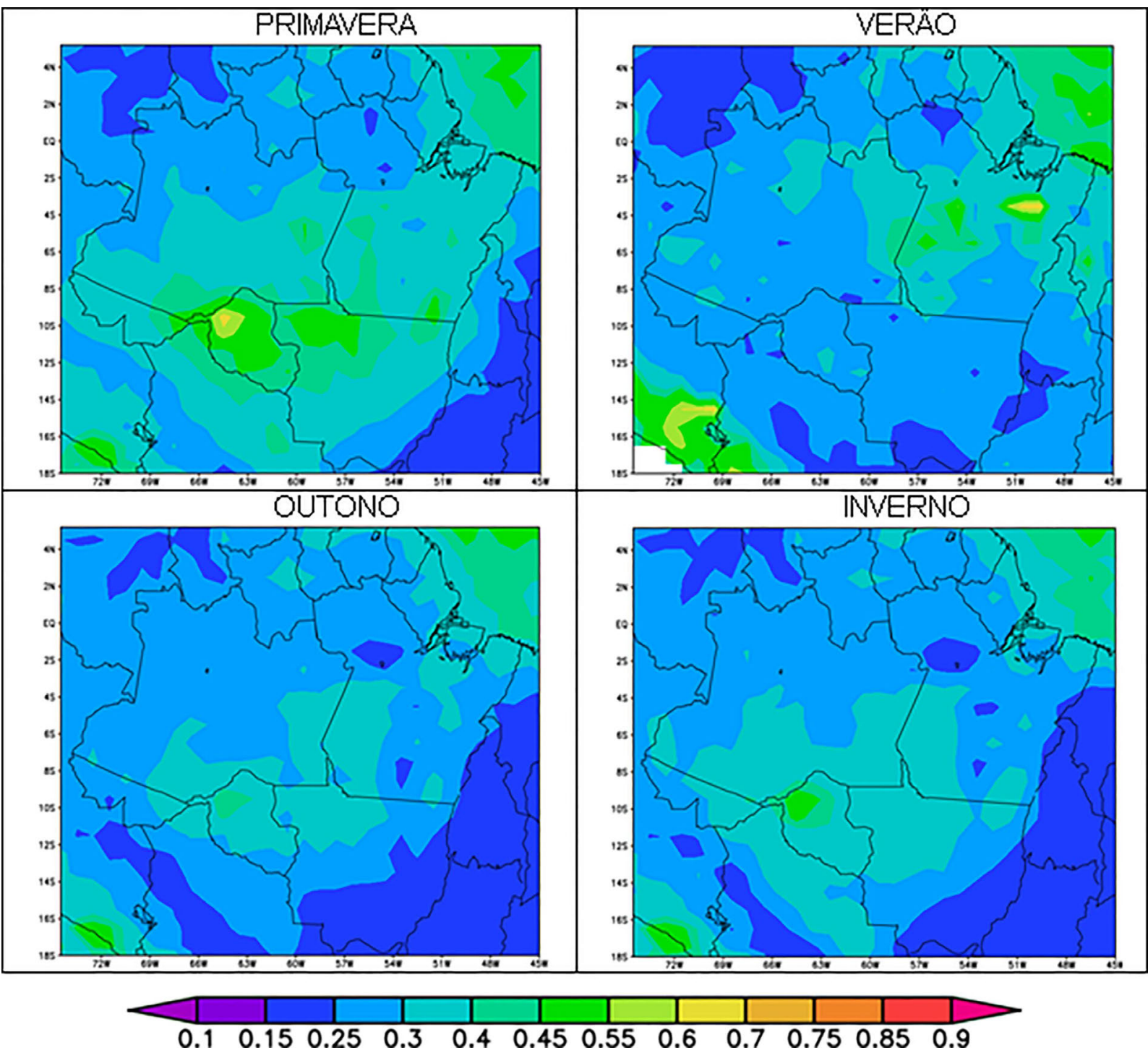

Figura 7 - Médias sazonais de espessura ótica dos aerossóis do sensor OMI, na região da Norte da América do sul para o período de 2005 a 2019.

deste estão localizadas no litoral e as mesmas contribuem como emissores de aerossóis para atmosfera devido as emissões por queima de combustíveis fósseis através dos veículos automotivos e indústrias.

Outro fator que pode estar associado é a domainancia da pluma de aerossóis associada com a advecção de poeira do deserto do Saara (Yamasoe, 1999; Goudie e Middleton, 2006), principalmente sobre a região do litoral é a maior influência desta pluma nas propriedades ópticas da atmosfera na região Nordeste ocorre durante o primeiro semestre do ano, entre os meses de janeiro e maio (Rosário, 2011).

\section{Conclusões}

A análise da variabilidade da EOA sobre a América do sul indica que apesar das diferentes características cli- máticas das sub-regiões abordadas no estudo existe um comportamento sazonal predominante com altos valores nas estações do verão e da primavera (estações secas) e baixos nos estações do outono e inverno (estações chuvosas) estando relacionado com a ocorrência de precipitação sobre as regiões nas épocas descritas com exceção da região nordeste que apresenta pouca variação nos valores de EOA ao longo do ano.

É bem visível nos resultados que a região do Cone Sul tem valores muito abaixo das demais regiões, dessa forma, pode-se afirmar mais uma vez que a influencia da chuva mais constante é uma variável determinante para os valores de EOA.

Os anos de 2005, 2007 e 2010 apresentaram altos valores de EOA nas regiões da Amazônia Internacional e Nordeste possivelmente relacionados com períodos de seca nas regiões. 


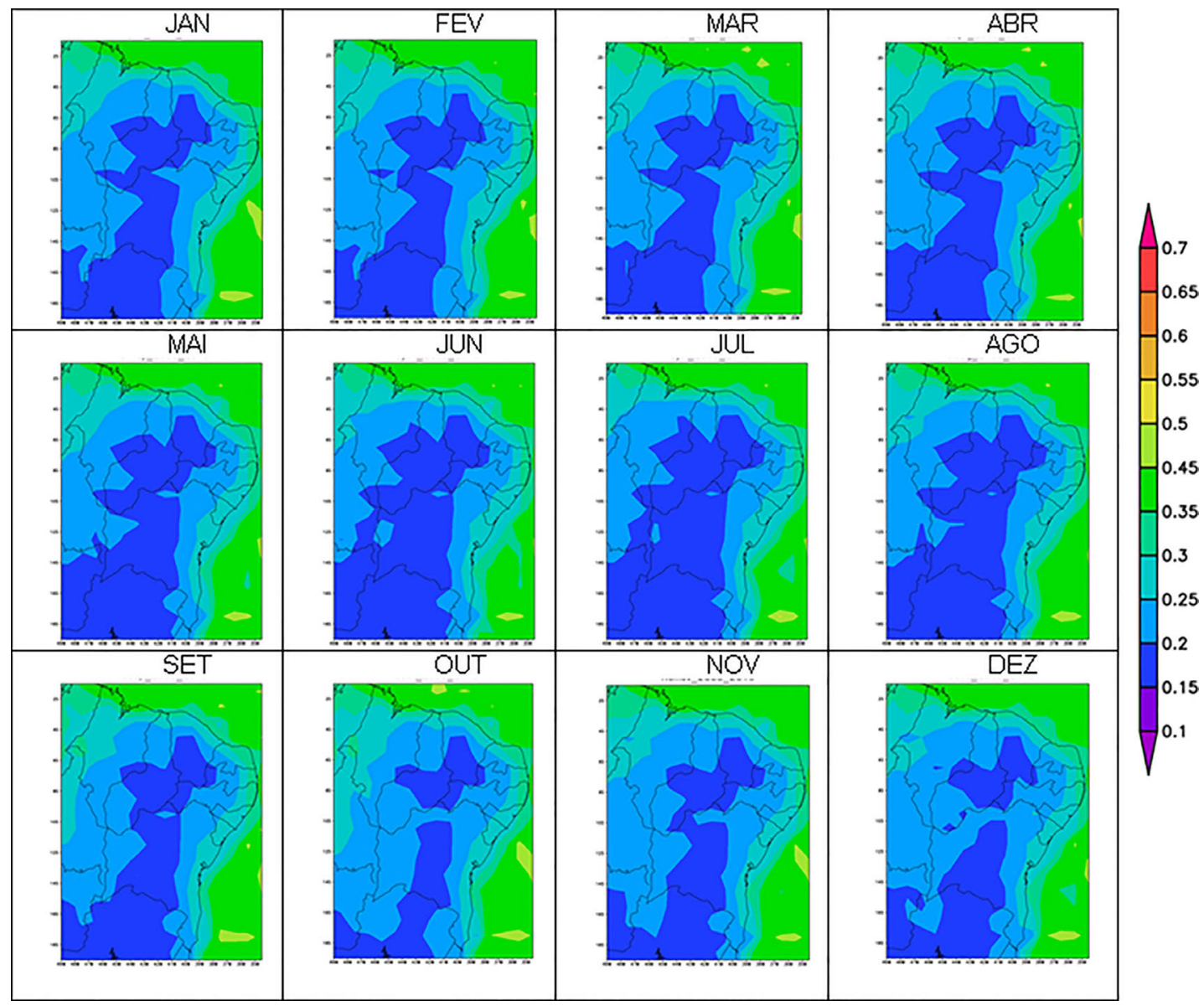

Figura 8 - Médias mensais de espessura ótica dos aerossóis do sensor OMI, na região do Nordeste do Brasil para o período de 2005 a 2019.

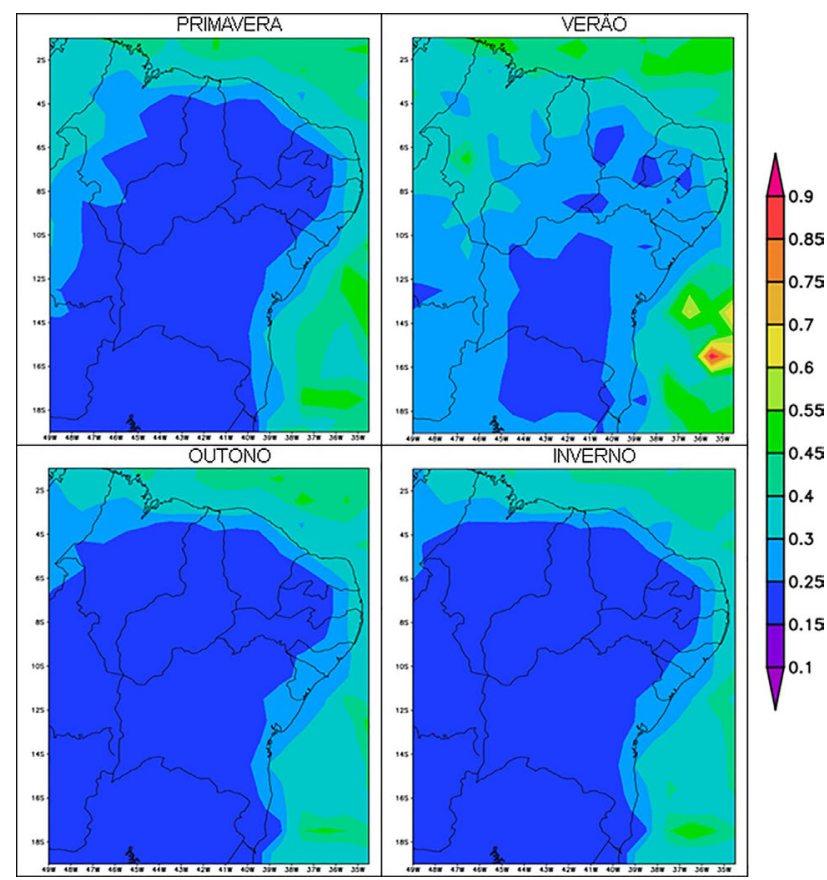

Figura 9 - Médias sazonais de espessura ótica dos aerossóis do sensor OMI, na região Nordeste do Brasil para o período de 2005 a 2019. 
$\mathrm{Na}$ análise das médias mensais, observa-se padrões semelhantes com os maiores valores sempre ocorrendo sobre as mesmas áreas somente com variação do seu máximo conforme mês analisado. Nas regiões litorâneas sempre se observa valores mais altos em relação aos do interior do continente com destaque na região Nordeste indicando possível influência de aerossóis provenientes do oceano juntamente com a atuação de emissões antropogênicas locais pela presença de grandes centros urbanos. De acordo com os resultados obtidos os passos futuros serão analisar a influencia de sistemas meteorológicos específicos atuantes em cada região analisada e como eles influenciam no transporte dos aerossóis e fazer comparações multissensorial dos dados de aerossóis para a região da América do Sul (fotômetro solar, sensores MODIS e OMI).

Pensando nas limitações a maior delas foi a indisponibilidade de uma rede mais ampla e com maior período de medição de fotômetro solar sobre a área analisada.

\section{Referências}

ACEITUNO P. Relation Entre La Posicion Del Anticiclon Subtropical Y La Precipitación En Chile. Relatório Do Projeto No E.551.791. Santiago: Departamento de Geofísica da Universidade do Chile, 14 p., 1980.

ALVES, C. Aerossóis atmosféricos: perspectiva histórica, fontes, processos químicos de formação e composição orgânica. Química Nova, v. 28, n. 5, p. 859-870, 2005.

AHLM, L.; NILSSON, D.; KREJCI, R.; MÃARTENSSON, R., VOGT, M., ARTAXO, P. et al. A comparison of dry and wet season aerosol number fluxes over the Amazon rain forest. Atmospheric Chemistry and Physics, v. 10, n. 6, p. 3063-3079, 2010.

ANDRADE, K.M. Climatologia E Comportamento Dos Sistemas Frontais Sobre A América Do Sul. Mestrado em Meteorologia, Instituto Nacional de Pesquisas Espaciais, São José dos Campos, 2005.

ARTAXO, P.; OLIVEIRA, P.H.; LARA, L.L.; PAULIQUEVIS, T.M.; RIZZO, L.V.; JUNIOR, C.P.; PAIXÃO, M.A.; LONGO, K.M.; FREITAS, S.;CORREIA, A.L. Efeitos climáticos de partículas de aerossóis biogênicos e emitidos em queimadas na Amazônia. Revista Brasileira de Meteorologia, v. 21, n. 3a, p. 168-22, 2006.

BETANCOURT, J.L.; LATORRE, C.; RECH, J.A.; QUADE, J.; RYLANDER, K.A. A 22.000-year record of monsoonal precipitation from Northern Chile's Atacama Desert. Science, v. 289 p. 1542-1546, 2000.

BIBI, H.; ALAM, K.; CHISHTIE, F.; BIBI, S.; SHAHID, I. et al. Intercomparison of MODIS, MISR, OMI, and CALIPSO aerosol optical depth retrievals for four locations on the Indo-Gangetic plains and validation against AERONET data. Atmospheric Environment, v. 100, n. 111, p. 113126, 2015.

BUCHARD, V.; DA SILVA, A.M.; COLARCO, P.R.; DARMENOV, A.; RANDLES, C.A. et al. Using the OMI aerosol index and absorption aerosol optical depth to evaluate the
NASA MERRA Aerosol Reanalysis. Atmospheric Chemistry and Physics, v. 15, n. 10, p. 5743, 2015.

BUSTAMANTE, T. Historia De La Conservación Ambiental En Ecuador: Volcanes, Tortugas, Geólogos Y Políticos. Quito: Flacso Ecuador, 2016.

CARVALHO, L.M.V.; JONES, C.; LIEBMANN, B. The South Atlantic convergence zone: Intensity, form, persistence, and relationships with intraseasonal and interannual activity and extreme rainfall. Journal of Climate, v. 17, n. 1, p. 88-108, 2004.

DOBBER, M.R.; DIRLSEM, R.J.; LEVELT, P.F.; VAN DEN OORD, G.H.J.; VOORS, R.H.M. et al. Ozone monitoring instrument calibration. IEEE Transactions on Geoscience and Remote Sensing, v. 44, n. 5, p. 1209-1238, 2006.

CRUTZEN, P.; ANDREAE, M. Biomass burning in the tropics: Impact on atmospheric chemistry and biogeochemical cycles. Science v. 250, n. 4988, p.1669-1678, 1990.

DRUMOND A.; NIETO, R.; GIMENO, L.; AMBRIZZI, T. A Lagrangian identification of major sources of moisture over Central Brazil and La Plata Basin. J. Geophys. Res., v. 113, D14128, 2008.

DURÁN-QUESADA, A.M.; REBOITA, M.S.; GIMENO, L.; NIETO R. The role of the tropics in the global water cycle: Precipitation and moisture transport in Tropical America. In: Esa-Esrin Conference: Earth Observation and Water Cycle Science: "Towards A Water Cycle MultiMission Strategy", Frascati, Itália, 2009.

DUNCAN, B.N.; YOSHIDA, Y.; FOY, B.; LAMSAL, L.N.; STREETS, D.G. et al. The observed response of Ozone Monitoring Instrument (OMI) NO2 columns to NOx emission controls on power plants in the United States: 20052011. Atmospheric Environment, v. 81, n. 1, p. 102-111, 2013.

EDUARDO ARAGÓN, L. A dimensão internacional da Amazônia: um aporte para sua interpretação. Revista NERA, v. 21, n. 42, p. 14-33 2018.

FEARNSIDE, P.M. Desmatamento na Amazônia: dinâmica, impactos e controle. Acta amazônica, v. 36, n. 3, p. 395-400, 2006.

FINLAYSON-PITTS, B.J.; PITTS, J.N. Chemistry Of The Upper And Lower Atmosphere: Theory, Experiments And Applications. Cambridge: Academic Press, 1999.

GARREAUD, R.D.; WALLACE, J.M. The diurnal of convective cloudiness over the Americas. Monthly Weather Review, v. 125, n. 12, p. 3157-3171, 1997.

GONTIJO, G.A.; PEREIRA, A.A; OLIVEIRA, E.D.S; JÚNIOR, F.W.A. Detecção de queimadas e validação de focos de calor utilizando produtos de Sensoriamento Remoto. In: Anais $1^{\circ}$ Simpósio Brasileiro de Sensoriamento Remoto, Curitiba, p. 7966-7973, 2011.

KAUFMAN, Y.J.; TANRÉ, D.; BOUCHER, O. A satellite view of aerosols in the climate system. Nature, v. 419, n. 6903, p. 215-223. 2002.

KODAMA, Y. Large-scale common features of sub-tropical precipitation zones (the Baiu Frontal Zone, the SPCZ, and the SACZ). Part I: characteristics of Subtropical Frontal Zones. Journal of Meteorological Society of Japan, v. 70, n. 4, p. 813-835, 1992.

LENTERS, J.D.; COOK, K.H. On the origin of the Bolivian high and related circulation features of the South American cli- 
mate. Journal of the Atmospheric Sciences, v. 54, n. 5, p. 656-678, 1997.

LEVELT, P.F.; HILSENRATH, E.; LEPPELMEIER, G.W.; VAN DEN OORD, G.H.J.; BHARTIA, P.K.; et al. Science objectives of the ozone monitoring instrument. IEEE Transactions on Geoscience and Remote Sensing, v. 44, n. 5, p. 1199-1208, 2006.

MARENGO, J.A.; LIEBMANN, B.; VERA, C.S.; NOGUÉSPEAGLE, J.; BÁEZ, J. Low-frequency variability of the SALLJ. CLivAR Exchanges, v. 9, n. 1, p. 26-27, 2004.

MARENGO, J.A.; TOMASELLA, J.; ALVES, L.M.; SOARES, W.R.; RODRIGUEZ, D.A. The drought of 2010 in the context of historical droughts in the Amazon region. Geophysical Research Letters, v. 38, n. 12, P. L12703, 2011.

MARTINS, L.D.; HALLAK, R.; ALVES, R.C.; DE ALMEIDA, D.S.; SQUIZZATO, R. et al. Long-range transport of aerosols from biomass burning over southeastern South America and their implications on air quality. Aerosol Air Qual. Res, v. 18, n. 7, p. 1734-1745, 2018.

MOLION L.C.B. Climatologia da região amazônica: Mecanismos de precipitação. Revista Brasileira de Meteorologia, v. 2, n. 1, p. 107-117, 1987.

NASA - National Aeronautics and Space Administration. The World In A Hundred Snapshots: New Calculation Method Could Help Improve Climate Model Accuracy. Disponível em https://www.esrl.noaa.gov/, acesso em 14 de jul. de 2013.

OLIVEIRA, A.M. Estudo Do Impacto Dos Aerossóis Na Espessura Óptica Da Atmosfera Na Região Sul Do Brasil. M.Sc. Thesis, Universidade Federal de Pelotas, 2013.

PAIXÃO, M.A.; PIRES, C.; ARTAXO, P.; CORREA, A. et al. Climatologia das propriedades ópticas do aerossol na Amazônia com base na rede AERONET. In: Anais do XV Congresso Brasileiro de Meteorologia, 2008.

PEEL, M.C.; FINLAYSON, B.L.; MCMAHON, T.A. Updated world map of the Köppen-Geiger climate classification. Hydrol. Earth Syst. Sci., v. 11, p. 1633-1644, 2007.

PEREIRA, N.R. Avaliacao Ambiental Com Utilizacao De Tecnicas De Sensoriamento Remoto E Sistema De Informacoes Geograficas Para Fins De Planejamento Agricola: Estudo Aplicado Ao Municipio De Eng. Paulo De Frontin (RJ). Rio de Janeiro: Universidade Federal do Rio de Janeiro, 1997.
REBOITA, M.S.; IWABE, C.M.N., ROCHA, R.P.; AMBRIZZI, T. Análise de um ciclone semi-estacioná- rio na costa sul do Brasil Associado a Bloqueio Atmosférico. Revista Brasileira de Meteorologia, v. 24, n. 4, p. 407-422, 2009.

REBOITA, M.S.; KRUSCHE, N.; AMBRIZZI, T.; ROCHA, R.P.D.A. et al. Entendendo o tempo e o clima na América do Sul. Terrae Didatica, v. 8, n. 1, p. 34-50, 2012.

RODWELL, M.J.; HOSKINS, B.J. Subtropical anticyclones and summer monsoons. Journal of Climate, v. 14, n. 15, p. 3192-3211, 2001.

ROSÁRIO, N.M.E. Estudo da Variabilidade das Propriedades Ópticas dos Aerossóis sobre a América do Sul e dos Impactos do Efeito Radiativo Direto das Partículas de Queimadas. Tese de Doutorado, Instituto de Astronomia, Geofísica e Ciências Atmosféricas, Universidade de São Paulo, 212 p., 2011.

SETZER, A.W.; MORELLI, F. Diferenças na quantificação de focos de queima de vegetação conforme o satélite e o sensor do monitoramento. In: Anais $5^{\circ}$ Simpósio Sul-Americano sobre Controle de Incêndios Florestais, Campinas, São Paulo, abril/2011, São Paulo, p. 264-267, 2011.

SIQUEIRA, R.A. Estudo Numérico Do Efeito Dos Aerossóis De Queimadas Na Previsão De Chuvas Convectivas Na América Do Sul. Tese de Doutorado em Ciência do Sistema Terrestre, Instituto Nacional de Pesquisas Espaciais, 198 p., 2016.

TORRES, O.; AHN, C.; CHEN, Z. Improvements to the OMI near-UV aerosol algorithm using A-train CALIOP and AIRS observations. Atmospheric Measurement Techniques, v. 6, n. 11, p. 3257-3270, 2013.

WILKS, D.S. Statistical Methods In The Atmospheric Science. Cambridge: Academic Press, 649 p., 2006.

UVO, C.R.B.; A Zona de Convergência Intertropical (ZCIT) E Sua Relação Com A Precipitação Da Região Norte Do Nordeste Brasileiro. São José dos Campos: INPE, 1989.

UVO, C.B.; REPELLI, C.A.; ZEBIAK, S.E.; KUSHNIR, Y. et al. The relationships between tropical Pacific and Atlantic SST and northeast Brazil monthly precipitation. Journal of Climate, v. 11, n. 4, p. 551-562, 1998.

License information: This is an open-access article distributed under the terms of the Creative Commons Attribution License (type CC-BY), which permits unrestricted use, distribution and reproduction in any medium, provided the original article is properly cited. 